\title{
Guest Editors' Introduction to Special Issue on Race Relations and Racial Inequity in LIS
}

\author{
Renate Chancellor, Shari Lee and Anthony Dunbar
}

In the aftermath of George Floyd's death at the hands of the police, protests against racism and police brutality ignited in the United States and across the world. Nevertheless, the deadly violence against Black, Indigenous, and Other People of Color (BIPOC) has continued. To date, little action has been taken to prevent these and similar acts of cruelty, which also stand as testament to the longstanding history of systemic racism in the United States. These events have forced institutions of higher education to reckon with the realities of racial inequality. This has been the case in Library and Information Science (LIS), which has struggled to adequately address issues of race and racial inequity since the founding of the profession.

This special issue of Education for Information addresses this gap with an impressive array of pieces, covering a wide range of topics, from a diverse group of scholars. Renate Chancellor, Shari Lee, Anthony Dunbar, Rajesh Singh and Paige Deloach introduce the topic on race relations in LIS by contributing a thought piece following the Floyd killing and protests. Amber Matthews uses Critical Race Theory to counter contemporary revisionist perspectives in public libraries to illustrate how they further perpetuate monocultural normativity and structural racism. Ana Ndumu and Shaundra Walker introduce an HBCU-inspired framework to counter racist educational practices. Rajesh Singh and Kevin Rioux propose an Advanced Certificate in Social Justice for Information Professionals that offers both current LIS practitioners and LIS students a curriculum grounded in principles of social justice. Phillippe Mongeon, Alison Brown, Ratna Dhaliwal, Jessalyn Hill and Amber Matthews emphasize the lack of research on race by providing a bibliometric analysis of LIS scholarship. Collectively, these papers contribute new knowledge and offer actionable measures that can help move the discipline towards taking a proactive stance on racism and racial equity in LIS. 